\title{
Dairy farmer use of price risk management tools
}

\author{
C. A. Wolf ${ }^{1}$ \\ Department of Agricultural, Food, and Resource Economics, Michigan State University, East Lansing 48824
}

\begin{abstract}
Volatility in milk and feed prices can adversely affect dairy farm profitability. Many risk management tools are available for use by US dairy farmers. This research uses surveys of Michigan dairy farmers to examine the extent to which price risk management tools have been used, the farm and operator characteristics that explain the use of these tools, and reasons farmers have not used these tools. A 1999 survey was used to benchmark the degree to which dairy producers had used milk and feed price risk management instruments to compare with 2011 use rates. The surveys collected information about the farm characteristics such as herd size, farmland operated, business organization, and solvency position. Farm operator characteristics collected include age, education, and experience. Dairy farmer use of both milk and feed price risk management tools increased between 1999 and 2011. In 2011, herd size was positively related to the use of milk price risk management tools, whereas farms organized as a sole proprietorship were less likely to use them. Also in 2011, herd size and land operated were positively related to feed price risk management tools, whereas operator age was negatively related. Reasons why farmers had not used price risk management tools included basis risk, cost, lack of management time, cooperative membership, and lack of understanding. Conclusions include the need for educational programming on price risk management tools and a broader exploration of dairy farm risk management programs.
\end{abstract}

Key words: milk price, feed price, futures markets, risk management

\section{INTRODUCTION}

Recent years have witnessed an increasing amount of volatility in both milk and feed prices, which can adversely affect dairy farm profitability. Figure 1 displays US milk (all milk), corn, and soybean prices monthly from 1991 through 2010. All prices are those that farm-

Received December 2, 2011.

Accepted March 14, 2012.

${ }^{1}$ Corresponding author: wolfch@msu.edu ers receive. One clear trend is the increasing amount of variation in milk prices since 1995. One measure of volatility is the coefficient of variation, which is the standard deviation divided by the mean. The mean, standard deviation, and coefficient of variation in milk price, corn price, and soybean price at the farm level are displayed in 5-yr increments between 1991 and 2010 in Table 1. The all milk price is a weighted average of prices paid at the processing plants for milk from farmers (Novakovic, 2009). The all milk price includes both grades A (fluid quality) and B (manufacturing quality) milk. Because the price is at the plant, the all milk price does not consider hauling costs, producer assessments, cooperative dues, or any other marketing cost that the farmer bears. Corn and soybean prices are average prices received by farmers for those grains (USDA-NASS, 2011). Both farm milk and soybean prices had increasing coefficients of variation in each 5 -yr period. Milk, in particular, went from a stable price with a coefficient of variation of 5\% from 1991 to 1995 to a relatively volatile $20 \%$ in the 2006 to 2010 period. The increase in volatility in corn and soybeans was less dramatic but they were also relatively more volatile in recent years than in the 1991 to 1995 period. It is clear that US farmers face volatile output and input prices in the current economic environment.

The volatility of the producer milk and feed prices in recent years has led many policy makers, dairy industry participants, and researchers to conclude that risk management tools are increasingly important for dairy farmers. Many risk management tools are available that could be used by US dairy farmers today. Milk price has been shown to be the largest factor related to variation in dairy farm revenue (Wolf et al., 2009). With respect to milk (output) price risk, there are class III milk price futures contracts and options for each calendar mo 24 mo into the future. Class III price is farm price of milk used for cheese and is the primary driver of milk prices in the United States. Futures and options traded on the Chicago Mercantile Exchange (CME) are monthly contracts that cash settle when the class III price is announced. This contract began as the basic formula price (BFP) contract in 1997 and became the class III contract with Federal Milk Marketing Order Reform in January 2000. The monthly class III - milk for cheese- 


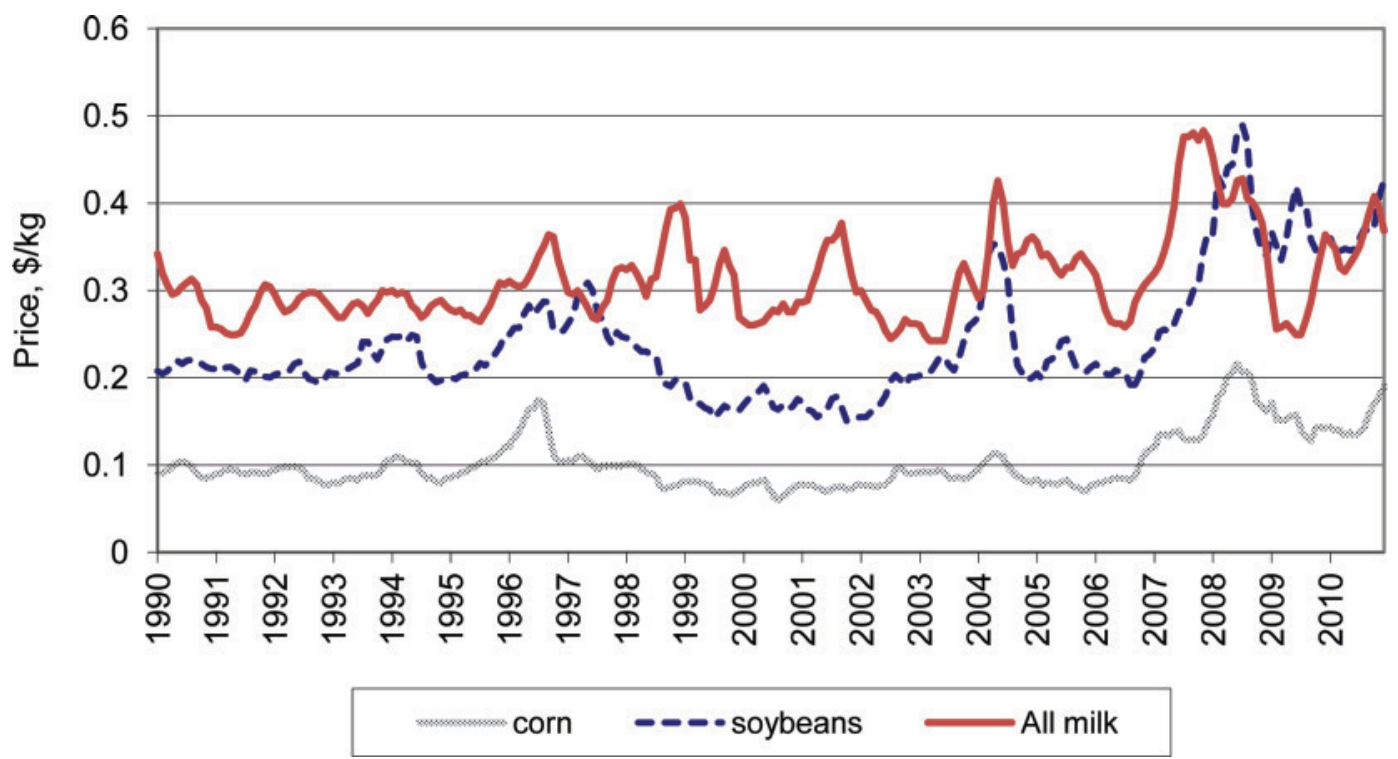

Figure 1. United States milk, corn, and soybean prices, 1990 to 2010. The all milk price includes both grades A (fluid quality) and B (manufacturing quality) milk. Color version available in the online PDF.

contract at the CME is $90,720 \mathrm{~kg}(200,000 \mathrm{lb})$. Class III contracts are offered for every calendar month as an enticement to hedgers (e.g., farmers, cooperatives, processors, and wholesalers) who get paid (or pay for product) monthly. Open interest-number of contracts outstanding - and volume in class III contracts has increased dramatically in the past decade, reflecting the desire of both sellers (e.g., farmers and cooperatives) and buyers (e.g., cheese processors) of milk to mitigate milk price risk.

Forward contracting can overcome some of the problems farmers may have with hedging including lumpi-

Table 1. Level and variation of monthly US milk, corn, and soybean prices $(\$ / \mathrm{kg}), 1991$ to 2010

\begin{tabular}{lccc}
\hline Time period & All milk & Corn & Soybeans \\
\hline 1991-1995 & & & \\
Mean & 0.28 & 0.09 & 0.21 \\
SD & 0.01 & 0.01 & 0.02 \\
CV & 0.05 & 0.10 & 0.08 \\
1996-2000 & & & \\
Mean & 0.31 & 0.10 & 0.22 \\
SD & 0.04 & 0.03 & 0.05 \\
CV & 0.12 & 0.29 & 0.22 \\
2001-2005 & & & \\
Mean & 0.31 & 0.08 & 0.21 \\
SD & 0.04 & 0.01 & 0.05 \\
CV & 0.14 & 0.13 & 0.24 \\
2006-2010 & & & \\
Mean & 0.35 & 0.14 & 0.33 \\
SD & 0.07 & 0.04 & 0.08 \\
CV & 0.20 & 0.25 & 0.25 \\
\hline
\end{tabular}

${ }^{1}$ The all milk price includes both grades A (fluid quality) and B (manufacturing quality) milk. ness, margin calls, and basis. Many dairy marketing cooperatives offer forward contracts for use by their farmer members that either reflect agreements with processors or retailers or are offset by futures and options contracts. The forward contracts offered to farmers through dairy cooperatives are often offered in smaller increments than the CME futures contracts. For example, $11,340 \mathrm{~kg}$ per month $(25,000 \mathrm{lb})$ is a common unit that is used for milk forward contracts through cooperatives. Milk marketing cooperatives also often have programs that handle margin requirements for members using those programs, which mitigate farm cash-flow implications. These programs lower the transactions cost of milk price risk management tools and should encourage their use but have not been widely and consistently used by most farmer members.

Similarly, dairy farmers have the ability to offset feed price risk using, for example, corn and soybean meal contracts at the Chicago Board of Trade. Corn, in 127-t (5,000-bushel) contracts, is traded for 5 calendar months each year, whereas soybean meal, in 91-t (100-short ton) contracts, is traded for 8 mo each year. Both corn and soybean meal futures and options contracts are traded for up to $4 \mathrm{yr}$ into the future. The existence of these futures and options contracts facilitates forward contracts by local feed providers and cooperatives. The availability to offset feed and milk price risk allows producers to potentially manage price risk around a milk price minus feed price margin, which is directly correlated with farm profitability (Wolf, 2010).

Dairy livestock gross margin (LGM) insurance is subsidized insurance that locks in a margin between 
class III milk price and a weighted average of corn and soybean meal prices with the weights and deductibles chosen by the farmer within certain ranges (Valvekar et al., 2010). Dairy LGM has been available in some parts of the United States since 2008 but the funding for premium subsidies to date has been small, which has limited its use. Part of the discussion regarding the next US farm bill, scheduled for 2012 but likely to be later, has included increased government subsidization of dairy LGM or a program with similar characteristics.

Despite both the motivation and ability to directly offset input and output price risk, use of these tools by dairy farmers has been limited to date. This research used surveys of Michigan dairy farmers in 1999 and 2011 to examine the extent to which risk management tools have been used, the farm and operator characteristics related to the use of these tools, and reasons farmers have not used these tools.

\section{MATERIALS AND METHODS}

\section{Survey}

The data used were collected from surveys of Michigan dairy farmers in 1999 and 2011. The 1999 survey of 1,500 farms randomly selected from the Michigan Department of Agriculture list of operations with a license to ship milk resulted in 458 useable responses (30.5\% response rate). The 1999 survey results are summarized in Wolf et al. (2000). The 2011 survey of 1,100 farms randomly selected from the then-current Michigan Department of Agriculture (Lansing) list of operations with a license to ship milk resulted in 225 useable responses (20.5\% response rate). Both surveys used the Dillman method (Dillman et al., 2009), with an initial survey followed by a reminder card and a second survey for nonrespondents. The 1999 survey is used to benchmark the degree to which dairy producers were using risk management instruments to compare with 2011 use rates.

Both surveys collected information about the farm characteristics such as herd size, land operated, business organization, and solvency position as well as the farm manager (e.g., age, education, and experience). Of particular interest to this research, the survey collected information on whether the farm had to that date used milk or feed price risk management tools. Specifically, the survey inquired about the use of futures, options, and forward contracts for milk or feed. Because some years or periods are likely to be more favorable for risk management tool use, the questions in both 1999 and 2011 were whether these tools had been used at any point in time rather than in the particular year of that survey.
The 2011 survey followed up the use of risk management questions by asking those who had not used those tools why they had not. Included were options related to the cost, convenience, and complications of using the risk management tools as well as the opportunity to fill in other reasons.

The summary results below reveal that the average herd size was larger than US Department of Agriculture statistics indicate but in line with typical commercial Michigan dairy farms. The range of herd size was broad and indicates that managers of all types of herds responded. Although the sample in both years was randomly drawn from a list of all grade A producers in Michigan, nonresponse was not explicitly controlled for and results should be viewed in that context.

\section{Data Analysis Methods}

Summary statistics used include the mean, standard deviation, and coefficient of variation, which is the ratio of the standard deviation to the mean. By standardizing the variation with the mean of that variable, the coefficient of variation allows comparison of the relative variation of 2 series. Summary statistics and correlations were calculated in Stata Version 12 software (StataCorp LP, College Station, TX).

To examine which farm operation and operator characteristics were related to price risk management tool use we used a probit estimation. The probit model is defined as $\operatorname{Pr}(\mathrm{y} \neq 0 \mid \mathrm{x})=\Phi(\mathrm{xb})$ where $\Phi$ is the standard cumulative normal distribution. The probit estimation has the form $\mathrm{y}=\mathbf{b}^{\prime} \mathrm{x}+\mathrm{e}$, where $\mathrm{y}=1$ for farms that have used milk or feed price risk management tools, $\mathrm{y}=0$ for farms that have not used price risk management tools, $\mathbf{b}$ is a vector of coefficients, and $\mathrm{e}$ is an error term. The explanatory variables (x) are farm and operator characteristics discussed below. The probit estimation yields coefficients that reflect the effect of a unit change in each explanatory variable on the probability of using risk management tools. Marginal effects, which are the derivative of the probability with respect to that variable calculated at the mean, are also reported. That is, the marginal effect of herd size is the change in the probability of the left-hand side variable happening (i.e., adopting milk or feed price risk management tools) if that explanatory variable were increased by 1 cow at the mean.

Following past research on risk management tool use, it was hypothesized that farm and operator characteristics both influence and are influenced by farm risk management plans. Current herd size indicates the investment in dairy production to this point and is expected to be positively related to use of risk management tools. This positive relationship is hypoth- 
esized to occur because these farms are large enough to take advantage of the offered contracts - especially in futures and options markets - as well as the fact that larger amounts of assets are potentially at risk. Similarly, land operated, another farm size measure, is expected to be positively related to farmer use of risk management tools. This relationship could result either from economies of size in using futures (i.e., decreasing average cost) or from issues with lumpiness of futures contracts for smaller producers (e.g., 90,720-kg milk contracts might be larger than farmer wishes to hedge in a given month; Shapiro and Brorsen, 1988).

The debt-to-asset ratio, which is calculated as farm liabilities divided by farm assets, measures the financial risk position of the farm. Higher debt-to-asset ratio indicates higher likelihood of insolvency or at least a smaller margin of error with respect to financial risk. The measure used here was whether the farm had a high-greater than 0.6-debt-to-asset ratio. Farms with greater than 0.6 debt-to-asset ratio are entering the danger zone with respect to financial solvency and may be more likely to use risk management tools to alleviate adverse financial outcomes (possibly because of lender requirement). Thus, the null hypothesis is that farms with high debt-to-asset ratio would be more likely to use risk management instruments.

Cooperative membership is a binary variable that indicates whether that farm is a member of a dairy marketing cooperative. Both major cooperatives in Michigan offer risk management tools to members. Cooperative membership could be positively related to using milk price risk instruments because of the availability of cooperative risk management tools. Alternatively, many farmers join cooperatives because the cooperative manages milk marketing. With a general lack of excess management time on dairy farms, managers might decide that they will use the cooperative management's marketing acumen and focus their attention elsewhere.

Business organization was an indicator variable that represented whether the farm was a sole proprietorship. All other forms of business organization [e.g., limited liability company (LLC), partnership, and corporation] were included in the not sole proprietorship category and thought to be more likely to use risk management tools because the larger management team more common to those organizations allows specialization in tasks.

Operator age was expected to be negatively related to use of risk management tools, whereas operator education was hypothesized to be positively related. That is, older operators were hypothesized to be less inclined to learn new tools - all else equal - whereas more educated operators were hypothesized more likely to use those tools.
These factors begin an examination of the patterns of use in price risk management tools by dairy farmers. Other factors that are likely to be important in affecting the use of price risk management tools were not collected and, thus, not considered. The most important factor not considered might be farmer attitude toward risk that is related to factors such as age, education, and financial position, but is broader and more comprehensive. After examining which factors were related to the use of risk management tools we examine the reasons that farms chose not to use any risk management tools.

\section{RESULTS AND DISCUSSION}

\section{Summary Statistics}

Table 2 displays summary statistics for the 1999 and 2011 survey samples. The average herd size of respondents in 2011 was 300 milk cows. This value is larger than the estimate of average herd size in Michigan for 2011, which was 172 (Michigan Dairy News Bureau, 2011). Note that the variation in the respondents' herd sizes, represented by the standard deviation, almost tripled in size between the 1999 and 2011 samples, indicating a much greater dispersion in herd size. Nonetheless, these respondents should be considered larger-than-average farm size, which means that, given the results discussed further below, the operations were more likely to use risk management tools. This herd size value was considerably larger than the 163 cow average from $12 \mathrm{yr}$ earlier, consistent with the growth in herd size around the United States. Membership in dairy cooperatives was higher for 2011 respondents than for 1999 respondents.

As might be expected, given the increase in milk price variation and volatility, the percent of respondents that had used milk price risk management tools at some point increased from 6 to $22 \%$ from the 1999 to 2011 sample. Similarly, but to a lesser degree, more respondents had used feed price risk management tools, with $39 \%$ indicating the use of feed price risk tools in 2011.

\section{Factors Related to the Use of Price Risk Management Tools}

The 2011 probit estimation results can be found in Table 3. The 1999 estimation results are not presented, as there were no significant explanatory variables for the use of milk price risk management, whereas only herd size was a significant explanatory variable related to the use of feed risk management tools. Larger herds tend to purchase more of their feed, which might ex- 
Table 2. Summary statistics (mean values with SD in parentheses) ${ }^{1}$

\begin{tabular}{lcc}
\hline Variable & 1999 Sample & 2011 Sample \\
\hline Herd size, no. of milk cows & $163^{*}(244)$ & $300^{*}(684)$ \\
Land operated, ha & $270(218)$ & $318(455)$ \\
Operator age, yr & $54.0(12.1)$ & $51.7(11.5)$ \\
Operator education, yr & $13.0(2.0)$ & $12.8(1.7)$ \\
Sole proprietors, \% yes & 50 & 53 \\
Use dairy coop, \% yes & $89^{*}$ & $95^{*}$ \\
Average coop membership, yr & 28 & 24 \\
Use milk price risk tools, \% yes & $6^{*}$ & $22^{*}$ \\
Use feed price risk tools, \% yes & $32^{*}$ & $39^{*}$ \\
Responses, no. & 458 & 225 \\
\hline
\end{tabular}

${ }^{1}$ Milk price risk tools include forward contracts, futures, and options. Feed price risk tools include forward contracts, futures, and options for feed (e.g., corn and soybean meal).

*Indicates that the 1999 and 2011 mean values within a variable differed at a $95 \%$ confidence level using paired $t$-tests.

plain the positive relationship with feed risk management tools.

For the 2011 sample, the model correctly predicted the use of milk price risk management tools $81 \%$ of the time and feed price risk management tools $74 \%$ of the time. With respect to explaining the use of milk price risk management tools in the 2011 survey, herd size was positively related to the use of those tools, whereas farms organized as sole proprietors were less likely to have used them (Table 3). The marginal effects described how much the probability of use increased (or decreased) as that variable changed by 1 unit for continuous variables or was true (as opposed to false) for binary variables. The marginal effect of herd size on milk price risk management tools was 0.0002 , which means that the probability of the farm having used milk price risk management tools increased by $2 \%$ for every 100-cow increase in herd size. Considering that it is usually optimal to hedge less than the entire amount of production in any given month and that futures and options are sold through the exchanges in whole increments, larger herds are more able to take advantage of the futures and options contracts that are $90,720 \mathrm{~kg}$ $(200,000 \mathrm{lb})$ per month than are smaller herds. Many herds can use tools through their dairy marketing cooperative that offer forward contracts for milk in smaller increments [e.g., $11,340 \mathrm{~kg}(25,000 \mathrm{lb})$ per month] to help alleviate this issue.

The likelihood of the farm using milk price risk management tools decreased by $12.5 \%$ if the operation was organized as a sole proprietor. Farms that are not sole proprietors, such as limited liability companies (LLC) and partnerships, may have larger management teams, enabling specialization to more closely manage issues such as price risk management.

Considering feed price risk management tools, herd size and land operated were positively related to their use, whereas operator age was negatively related to their use. Similar to the use of milk price risk management tools, it is intuitive that larger herds, which tend to purchase larger quantities of feed, would be interested in managing feed price risk. With respect to the relationship with land operated, note that the analysis to this point has strictly considered the use of, for example, corn contracts as input price risk management. However, it is entirely possible that a dairy farm, which derives the majority of its revenue from the milk-

Table 3. Explaining use of risk management tools, 2011

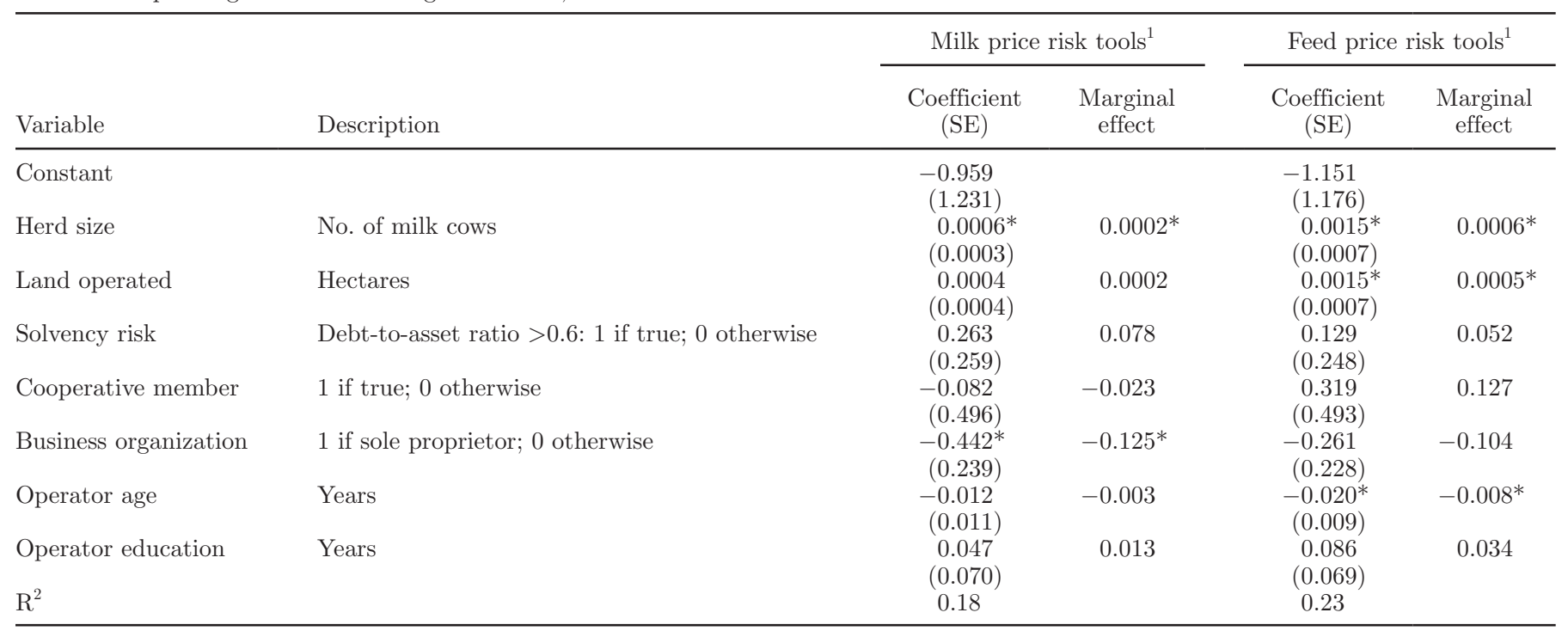

${ }^{1}$ The dependent variable is whether farms have used milk or feed price risk management tools.

*Indicates that the variable was significant at the $P=0.1$ level. 
ing herd, could be selling as well as purchasing these commodities. Many Michigan farms are diversified into crop production as a profit center in addition to their dairy enterprise. For these cases, they could use corn futures contracts to hedge output price risk. This may help explain why land operated was positively related to feed price risk tool use but unrelated to the use of milk price risk tools. Operator age having a negative relationship to feed price risk management tools may be related to the reluctance of older operators to adopt new technology.

\section{Reasons Farmers Had Not Used Price Risk Management Tools}

Futures and options contracts have existed for many years with a large and liquid market for many commodities. Past research has examined farmer use of hedging instruments. In particular, many studies have examined the contradiction between the risk reduction effects that are possible using hedging and the small proportion of farmers that use those instruments (Carter, 1999). Some research has attributed farmer aversion to hedging to lack of understanding, margin calls, and basis risk (Frazier, 1984; Pennings and Meulenberg, 1997). One proposed solution in that case is education for farm managers. Tomek (1987) suggested that perhaps farmers were not underusing futures and options as much as some normative models implied was optimal because those models ignored important costs of hedging, such as transactions costs. Newbery and Stiglitz (1981) and Bond and Thompson (1985) suggested that producer use of futures markets was influenced by size of operation, transaction costs, the cost of information, and belief of bias in futures markets.

With respect to milk price risk management, Maynard et al. (2005) found that many existing dairy policies, including pooling milk revenues and the Milk Income Loss Contract (MILC), offset milk price risk and diminish the motivation for dairy farmers to use milk futures and options. However, the large and increasing volatility in recent years may provide sufficient motivation to overcome these policy effects. Further, the MILC program is on the chopping block in the next farm bill; thus, it may not remain to discourage farmer use of price risk management tools.

Table 4 displays the reasons that farmers gave for not having used any of the price risk management tools. Ninety-nine respondents had used neither type of price risk management tool to date, with most indicating more than one reason. As a share of the total responses $(\mathrm{n}=203)$, the most common reason given was basis risk. When a farmer uses a futures or options contract, they are locking in that portion of their milk or feed price risk, but the relationship between the cash and futures price (i.e., the basis) can be uncertain. Past research has examined the relative amount of basis risk when farmers use milk futures and its role in adoption of these tools (Maynard et al., 2005). For milk, the basis is defined as the difference between the cash price received for milk by farmers, the mailbox price, and the class III price, which is traded in the futures and options market. Because class III is a major component of milk price in most states and regions, it is expected to generate a large portion of the mailbox milk price variation. The basis is the portion of the mailbox milk price whose variation is not protected when the class III price is hedged. Each farm actually has its own basis because of individual protein, fat, and somatic cell premiums as well as hauling costs. Because no marketing order is $100 \%$ milk used for cheese, using the class III futures contract is to some extent a cross-hedge for all farmers. The basis risk has both intertemporal and spatial dimensions across farms and region of the United States. Class III price reflects the cheese price, which is national in nature. The basis reflects regional and local considerations, including over-order and quality premiums. If basis risk is as large as milk price risk, then little motivation exists to hedge milk price. The US Department of Agriculture reports a representative mailbox price for selected states and regions each month. Figure 2 displays the Michigan mailbox and class III (national) price from 1999 through 2010. It is clear that a great deal of variation exists in the milk price basis, which mitigates the motivation to hedge to some degree.

The second most common reason that Michigan dairy farmers had not used price risk management tools was cost. Using these tools includes fees for trades in the case of futures and options. The third most common reason was that the tools were difficult to use, which could be related to the costs in management time, which was mentioned by about $7 \%$ of respondents.

Table 4. Reasons why Michigan dairy farmers had not used price risk management tools, 2011

\begin{tabular}{lc}
\hline Reason & \% of Responses ${ }^{1}$ \\
\hline Basis risk & 22.2 \\
Cost & 18.7 \\
Difficult to use & 13.8 \\
Cooperative markets milk & 12.3 \\
Limited management time & 6.9 \\
Lack of understanding & 6.9 \\
Operation too small & 3.9 \\
Other & 15.3 \\
\hline
\end{tabular}

${ }^{1}$ Percentage of responses indicates the share of the 203 total responses provided, as many of the 99 respondents to this question (those who had not used risk management tools of any kind) provided more than 1 response. 


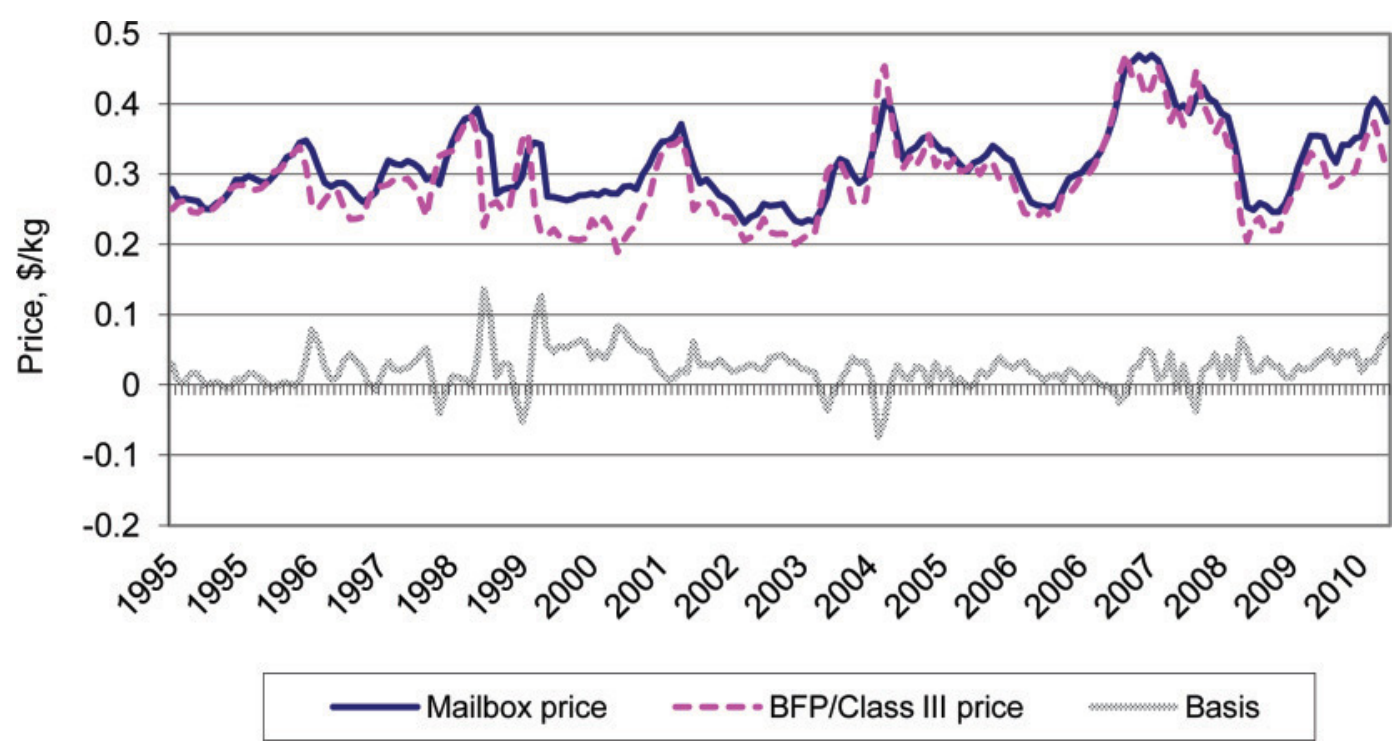

Figure 2. Class III and Michigan mailbox milk price with basis, 1999 to 2010. Color version available in the online PDF.

The next most common reason that price risk management tools had not been used was that the farm was a member of the cooperative to market their milk. Marketing milk, which includes balancing supply and demand with excess operating capacity and contracts with processors and retailers, is the reason that these dairy cooperatives exist. Michigan has several cooperatives operating and most of the survey respondents belonged to one of these. All of the cooperatives operating in Michigan in 2011 have milk forward contracts as well as futures and options tools available to members. However, these results would suggest that farmers view the cooperative marketing of milk as a substitute rather than a complement to farm-level price risk management tools.

Lack of understanding of the risk management tools was also mentioned by many respondents. Many cooperatives, brokers and University Extension personnel have presented programs to Michigan farmers in the past dozen years, but clearly, a need may exist for continued education if, as expected, the milk and feed prices continue to be a source of volatility in farm profitability.

A few respondents indicated that their operation was too small to effectively use the risk management tools. If producers were considering using the futures and options contracts directly, the contracts are for $90,720 \mathrm{~kg}$ of milk, which was the total monthly production for 103 average Michigan cows in 2010. Corn and soybean meal futures and options contracts also come in large increments. However, Michigan cooperatives offer milk price risk tools in smaller increments and local feed mills often forward contract smaller feed amounts.
A category entitled other was included along with a space to explain the reason. Although a wide variety of reasons were given, many commonalities were evident. The most common were that other producers they talked to had lost money using these tools, that using these tools was too stressful, and that they were opposed to these tools (with some respondents indicating that it was for religious reasons).

\section{CONCLUSIONS}

This research focused on factors related to Michigan dairy farmer adoption of price risk management tools. The use of both milk and feed price risk management tools significantly increased between 1999 and 2011. This increased use reflected the larger variation in both milk and feed prices. In the case of milk futures and options use, the markets (measured by contract volume and open interest) became larger and more liquid over that period. Dairy farm managers that had not used risk management tools for either milk or feed managed typically smaller herds. Farms organized as sole proprietorships were significantly less likely to have used milk price risk management tools. Those that did not use feed price risk management operated less land and were younger. The reasons that farmers indicated they had not used these tools included cost, basis risk, and lack of understanding. Another reason that was mentioned was that, particularly with respect to milk price risk, most dairy farmers are members of milk marketing cooperatives. On the flip side of that issue, cooperatives are serving a demand from at least a portion of farmer members by offering risk management programs. Coop- 
erative price risk management programs can facilitate farmer participation by offering contracts in smaller increments than the futures and options contracts offered on the commodity exchanges. Cooperative programs also may manage the margin account for the farmer, which many would find useful with respect to cash flow issues.

Perhaps the longer-run solution to dairy farm price risk management is dairy LGM insurance. Future national policy decisions such as funding for dairy LGM and which dairy policies are a part of the next farm bill will play a major role in which tools are available and how attractive they are to US dairy farmers. These policies and insurance contracts would likely cut down on farmers directly using their own price risk management tools but were not available or widely used in the period considered. Many ways exist that this research topic can be expanded and improved to inform decision makers in the dairy industry. One factor that was not considered was the risk attitude of the farmers. Models in economics and psychology could be used to examine how dairy farmer attitudes toward risk are formed and change over time and across farms. Additionally, although the present paper has examined only price risk management tools, they are part of a wider set of management tools used by farmers to manage risk. Dairy farms face many types of risk, including production, human resource, financial, institutional, and policy risk. Future research should consider a broader mix of risk management tools used by dairy farmers and evaluate effectiveness of these tools in a farm-wide context. Price volatility will continue to affect dairy farm profits. Educational programs can facilitate and encourage adoption of price risk management techniques. Dairy farmers who manage large, input-intensive farms are most likely to use price risk management tools. Educational efforts that consider these attributes are likely to be the most successful.

\section{REFERENCES}

Bond, G. E., and S. R. Thompson. 1985. Risk aversion and the recommended hedging ratio. Am. J. Agric. Econ. 67:870-872.

Carter, C. A. 1999. Commodity futures markets: A survey. Aust. J. Agric. Resour. Econ. 43:209-247.

Dillman, D. A., J. D. Smyth, and L. M. Christian. 2009. Internet, Mail and Mixed-Mode Surveys: The Tailored Design Method. John Wiley \& Sons Inc., Hoboken, NJ.

Frazier, J. H., Jr. 1984. Commentary. Review of Research in Futures Markets 4:29-30.

Maynard, L., C. Wolf, and M. Gearhardt. 2005. Can futures and options markets hold the milk price safety net? Policy conflicts and market failures in dairy hedging. Rev. Agric. Econ. 27:273-286.

Michigan Dairy News Bureau. 2011. Michigan dairy facts. Accessed Nov. 17, 2011. http://www.michigandairynewsbureau.org/index. php?option $=$ com_content\&view $=$ article\&id $=5 \&$ Itemid $=7$.

Newbery, D. M. G., and J. E. Stiglitz. 1981. The Theory of Commodity Price Stabilization: A Study in the Economics of Risk. Clarendon Press, Oxford, UK.

Novakovic, A. 2009. Changes in the farm price of milk over the last 100 years. Cornell Program on Dairy Markets and Policy Briefing Paper 09-1. Cornell University, Ithaca, NY.

Pennings, J. M. E., and M. T. G. Meulenberg. 1997. Hedging efficiency: A futures exchange management approach. J. Futures Mark. $17: 599-615$.

Shapiro, B. L., and B. W. Brorsen. 1988. Factors affecting farmers' hedging decisions. North Central J. Agric. Econ. 10:145-153.

Tomek, W. G. 1987. Effects of futures and options trading on farm incomes. Cornell University Agricultural Economics Staff Paper No. 87-9. Cornell University, Ithaca, NY.

USDA-NASS (US Department of Agriculture, National Agricultural Statistics Service). 2011. Agricultural Prices. Annual Issues 1992 2011. Accessed Nov. 17, 2011. http://usda.mannlib.cornell.edu/ MannUsda/viewDocumentInfo.do?documentID $=1002$.

Valvekar, M., V. E. Cabrera, and B. W. Gould. 2010. Identifying costminimizing strategies for guaranteeing target dairy income over feed cost via use of the Livestock Gross Margin dairy insurance program. J. Dairy Sci. 93:3350-3357.

Wolf, C. A. 2010. Understanding the milk-to-feed price ratio as a proxy for dairy farm profitability. J. Dairy Sci. 93:4942-4948.

Wolf, C. A., J. R. Black, and J. Hadrich. 2009. Upper Midwest dairy farm revenue variation and insurance implications. Agric. Finance Rev. 69:346-358.

Wolf, C.A., S. Harsh, S. Bucholtz, A. Damon and J. Lloyd. 2000. Michigan Dairy Farm Industry: Summary and Analysis of the 1999 Michigan State University Dairy Farm Survey. Michigan Agricultural Experiment Station Research Report 573. Michigan State University, East Lansing. 